\title{
Medical History for Anesthesiologists: Continuation of a Primer
}

\author{
Manisha S. Desai, $M D^{\star}$ and Sukumar P. Desai, $M D^{\star \star}$ \\ ${ }^{*}$ Clinical Associate Professor of Anesthesiology, University of Massachusetts Medical School, Worcester, Masschusetts; ${ }^{*}$ Assistant Professor of \\ Anaesthesia, Harvard Medical School, Anesthesiologist, Brigham and Women's Hospital, Boston, Massachusetts
}

Editor's note: The absence of a recognized formal curriculum in anesthesia history means that many of us have known and unknown gaps in our knowledge. These gaps limit our ability to understand how things came to be, how things may become and how we can affect the future. I have asked Dr. Manisha Desai and Dr. Sukumar Desai to provide a primer on the history of medicine and anesthesia history. The goals of this primer are to educate and to help individuals target future study. Below is the second article in a continuing series.

\section{History of Science:}

Continuing with advances in the Classical Era, Aristotle [384-322 BCE] emphasized observation of the natural world and used scientific principles to explain natural phenomena such as motion, movements of celestial bodies, and properties of matter. In addition, he held a keen interest in biology. Similar to Plato's Academy, Aristotle founded a school in Athens called the Lyceum. His students and followers include Theophrastus, Strato, and Alexander III of Macedon (Alexander the Great).

Alexander III of Macedon founded Alexandria in Egypt. Alexandria became a great academic center and housed a magnificent library and museum. The mathematician Euclid, known for his contributions in geometry, worked in Alexandria. Archimedes [287-212 BCE] studied in Alexandria, but spent most of his career in Syracuse, Greece. His contributions included determination of the density of solids, geometrical properties of spheres and cylinders, applications of mechanical leverage, and the use of many large mirrors to concentrate the heat of the sun to set invading ships ablaze. Subsequent Greek contributions added greatly to our knowledge of celestial motion. The Romans conquered Greek territories by the end of the $1^{\text {st }}$ century $\mathrm{BCE}$, and their scientific contributions was dominated by practical applications of the principles elucidated by the Greeks. These included roadways, architecture, aqueducts, water-mills, heating and plumbing. The Romans improved upon earlier calendars and established the Julian system in honor of Julius Caesar in the $1^{\text {st }}$ century BCE. They also introduced formal education curricula with emphasis on the seven liberal arts-rhetoric, grammar, dialectic [these three constituting the trivium], arithmetic, geometry, astronomy, and music [the four constituting the quadrivium]. These liberal arts were believed to be more suitable for aristocrats, while medicine and architecture were considered technical applications more appropriately classified as crafts and trades. The Roman Empire lasted half a millennium and ended with the fall of Rome in 476 CE. This period is marked by the rise of Christianity and the spread of existing knowledge throughout southern Europe, North Africa, and Western Asia. During this period, Greek works were translated into Latin, Arabic, Hebrew, and other languages.

\section{History of Medicine:}

Ancient medicine in Egypt and Greece was marked by a belief in supernatural causes of disease, a notion that was dispelled by Hippocrates and his followers. The next giant of ancient medicine was Galen [130-201 CE] (Figure 1), who was born in Bergama, which is in present day Turkey. He formalized the many practices that had emerged after Hippocrates' death in 350 BCE. Achieving a balance in the four body fluids (blood, yellow bile, black bile, and phlegm) continued to be very important and physicians used a variety of methods to achieve such balance. Galen's work included animal vivisection and experimentation about physiological processes. He believed that an essential gaseous substance (pneuma) entered the body via the lungs, from where it went to the left ventricle and thence onto the brain. From the brain, psychic pneuma carried information to the rest of the body through nerves. Galen taught that food reached the liver from the stomach, and that blood was synthesized in the liver. $\mathrm{He}$ believed that veins carried blood to the tissues. For a brief period, he worked in the arena where gladiators fought and died. In this capacity, he was able to observe the beating human heart, pulsatile flow in arteries, movements of the chest and lungs, as well as peristaltic movements of the intestine. He showed that pulse was related to the heart beat, that arteries contained blood, that lungs expanded because of the negative pressure created by the diaphragm, that urine was formed in the kidney (not the bladder), and that voice originated in the larynx under the control of nerves. He used mixtures of plant extracts and chemicals, and for hundreds of years these mixtures were marketed as galenicals. His written works are summarized in 22 volumes, and his influence was so great that his doctrine remained unchallenged until the $16^{\text {th }}$ and $17^{\text {th }}$ centuries.

\section{History of Anesthesia:}

Among other techniques, alcohol, opium derivatives, cannabinoids, and belladonna derivates were used to provide sedation, analgesia, and amnesia to perform surgical operations. These were in use until the 1840 s when recreational use of nitrous oxide and ether gained popularity. It is unclear who deserves credit for the discovery of anesthesia, but we will briefly examine the roles played by key contributors and suggest one way to address this controversy.

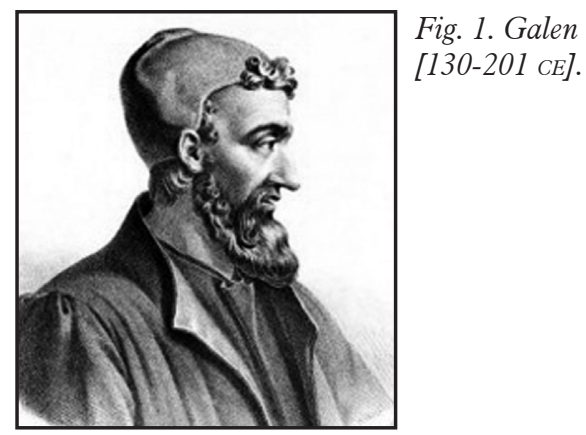

Humphrey Davy [1778-1829] studied properties of various gases while working at The Pneumatic Institute, Bristol, UK, among them nitrous oxide. He verified its effects on the nervous system and suggested that these properties might be used to advantage during surgical operations. However, neither he nor his colleagues followed up on this suggestion. In January 1842, medical student William Edward Clarke [1819-1898] unknowingly became the first person to use ether during a dental extraction. His professor, E.M. Moore, dissuaded him from carrying out any further administrations, and neither Moore nor Clark's biographers felt that Clarke had made a significant contribution. In 1842, Crawford Williamson Long [1815-1878]

Continued on Page 13 


\section{Primer... Continued from Page 12}

was aware of the recreational use of ether, and on March 30, 1842, he was the first to use ether during a surgical operation. He regularly administered ether during surgical procedures in his medical practice in rural Georgia. He is faulted for not publicizing his findings and for waiting until 1847 before publishing his work. During the mid 1840s, it was common for itinerant showmen to stage nitrous oxide demonstrations for purposes of entertainment. On December 10, 1844, during one such demonstration by Gardner Quincy Colton [1814-1898] in Hartford, Connecticut, dentist Horace Wells [1815-1848] observed the analgesic properties of nitrous oxide on a participant who had been accidentally injured. Wells underwent a painless dental extraction the next morning while Colton administered nitrous oxide. Wells used nitrous oxide extensively in his dental practice, a fact that was known to William Thomas Green Morton [18191868]. Wells wished to demonstrate the efficacy of nitrous oxide in Boston in January 1845 , but the administration was only partly successful because the medical student who volunteered to have his tooth extracted screamed. The student later admitted that he did not remember feeling any pain, but the damage was done. Wells was ridiculed as he left the amphitheater, and he sought credit for his contribution in Europe and in the US. However, his life was never the same, and in 1848 he committed suicide in a New York prison after being arrested for attacking women.

Morton was aware of the properties of nitrous oxide and ether and was persuaded by Charles Thomas Jackson [1805-1880] to use ether. Morton conducted several experiments on lower species, and finally used it successfully during tooth extraction on Ebenezer Hopkins Frost on September 30, 1846. Morton also convinced Henry Jacob Bigelow [1818-1890] and Jonathan Mason Warren [1811-1867], staff physicians at Massachusetts General Hospital, about the efficacy of his technique. He won approval from John Collins Warren [17781856], chief-surgeon and founder of Massachusetts General Hospital, to administer ether during a surgical procedure. This demonstration, on October 16, 1846, was successful, and that day is now celebrated as Ether Day. Morton tried to conceal the identity of the active ingredient (he called the anesthetic "letheon" in his attempt to patent his treatment). These attempts were unsuccessful, and a battle for the credit of discovering anesthesia raged in the popular press and congress for over two decades.
The matter was never resolved legally, with Morton, Jackson, and Long being the main contenders.

We suggest the following resolution to the controversy over the discovery of anesthesia. The process is best broken down into components and credit distributed according to clearly defined roles played by the various participants. Humphry Davy deserves credit for first suggesting that nitrous oxide possessed analgesic properties. William Edward Clarke should be credited with the first use of ether for a dental procedure, whereas Crawford Williamson Long deserves credit for the first use of ether during general surgery. Horace Wells deserves credit for the first use of nitrous oxide during dental surgery. Charles Thomas Jackson deserves credit for suggesting to William Thomas Green Morton that ether might be used as an anesthetic. William Thomas Green Morton deserves credit for conducting experiments on ether, demonstrating its efficacy publicly, and for spreading word about its efficacy throughout the medical community. By abandoning attempts to give credit to one individual, we can truly recognize efforts that led to the discovery of anesthesia.

Coming up next: We shall discuss other advances made in science during the dark ages and the role of Vesalius and others in finally ending the strangulating influence of Galen's beliefs. We then explore the evolution of early anesthesia beyond simple administration of ether or nitrous oxide.

\section{Additional Reading:}

1. Keys TE. The History of Surgical Anesthesia. Park Ridge, IL: Wood Library-Museum of Anesthesiology; 1996

2. Lindberg DC. The Beginnings of Western Science, $2^{\text {nd }}$ Edition. Chicago, IL: University of Chicago Press; 2007.

3. Singer C, Underwood EA. A Short History of Medicine, $2^{\text {nd }}$ Edition. Oxford, England: Oxford University Press; 1962.

4. Temkin O. Galenism: Rise and Decline of a Medical Philosophy. Ithaca, NY: Cornell University Press; 1973.

\section{Trends... Continued from Page 6}

Saver JL. Evidence of publication bias in reporting acute stroke clinical trials. Neurology. 2006;67:973-9.

16. Okike K, Kocher MS, Mehlman CT, Heckman JD, Bhandari M. Publication bias in orthopaedic research: an analysis of scientific factors associated with publication in the Fournal of Bone and Foint Surgery. F Bone Foint Surg Am. 2008;90:595-601.

17. Olson CM, Rennie D, Cook D, Dickersin K, Flanagin A, Hogan JW, et al. Publication bias in editorial decision making. $7 A M A$. 2002; 287:2825-8. 